\title{
A STUDY OF DEPRESSION AMONG ASTHMATIC PATIENTS IN A TERTIARY HOSPITAL
}

\author{
Samyuktha Gangadhar1, Kasthuri Pandiyan² \\ ${ }^{1}$ Consultant Psychiatrist, Department of Psychiatry, Apollo Clinic, Bellandur, Bangalore, Karnataka. \\ ${ }^{2}$ Associate Professor, Department of Psychiatry, MVJ and HC, Dandupalya, Hoskote, Bangalore, Karnataka.
} \begin{abstract}
BACKGROUND

Depression among asthmatics is associated with poor asthma control and quality of life. The prevalence of depression in asthmatics varies from $8 \%$ to $55 \%$ in various studies.(1,2) Depressive symptoms are associated with increased asthma severity, poorer outcome and greater risk for hospitalisation in patients with asthma. Thus, knowledge about prevalence and effect of depression in asthmatic illness may have important implications for identification and appropriate treatment of these patients. Aims and Objectives- The aim of this study is to study the prevalence of depressive disorders in asthmatic patients.
\end{abstract}

\section{MATERIALS AND METHODS}

A hospital-based cross-sectional study conducted in a tertiary care health centre in Puducherry, India. Seventy patients of asthma diagnosed using spirometric criteria, aged 18 - 64 years of both sexes were studied. Patients were screened for depression using PHQ-9 and patients having positive scoring were evaluated in detail by the clinician and ICD-10 criteria was used to confirm the diagnosis of depression. This study is a part of larger study, where patients were followed up for 6 months.

\section{RESULTS}

In the sample of 70 asthma patients, 40 patients had depressive disorders (Total prevalence- 57.1\%; 15.7\%- mild, 24.3\%moderate, $14.3 \%$ - moderately severe, $2.9 \%$ - severe depression). Majority of them being married, belonging to rural background and of lower- and upper-lower income. Female population having predominance. Mean age group being 30 for males and 35 for females.

\section{CONCLUSION}

There is a high prevalence of depression among patients suffering from asthma.

\section{KEYWORDS}

Depression, Asthma, Adults.

HOW TO CITE THIS ARTICLE: Gangadhar S, Pandiyan K. A study of depression among asthmatic patients in a tertiary hospital. J. Evolution Med. Dent. Sci. 2018;7(18):2181-2184, DOI: 10.14260/jemds/2018/490

\section{BACKGROUND}

Depression in the present world is a major contributor of morbidity and mortality with life-time prevalence in the general population of almost 20\%. The Disability Adjusted Life Years (DALY) of depression accounts to a total of $4.4 \%$ in all ages and gender (Women= 5.5\%, men= 3.4\%). Years of Life Lived with Disability (YLD) for all ages and both sexes attributable to depression is $11.9 \%$ (males $=9.75 \%$, females $=$ $14.5 \%) .(3)$

Asthma is a chronic medical condition and a serious public health problem in industrialised countries associated with significant morbidity and functional impairment, currently affecting 300 million people globally. The Disability Adjusted Life Years (DALY) of asthma is $1.4 \%$ and YLD of $2.3 \%$ in males, $1.8 \%$ in females and a total of $2.1 \%{ }^{(4)}$

Asthma patients tend to have higher levels of stress and negative emotions such as panic, fear, irritability, depression and bipolar disorders.(5) Recent reviews have found that depressive symptoms are more common in asthma patients than the general population. $(6,7)$ Nearly, $50 \%$ of asthma patients have depressive symptoms. ${ }^{(8)}$

'Financial or Other Competing Interest': None.

Submission 12-03-2018, Peer Review 11-04-2018,

Acceptance 18-04-2018, Published 30-04-2018.

Corresponding Author:

Dr. Kasthuri Pandiyan,

Associate Professor, MVJ Medical College Research Hospital,

Dandupalya, Hoskote, Bangalore-562114, Karnataka.

E-mail: drkasthurip@gmail.com

DOI: $10.14260 /$ jemds $/ 2018 / 490$
Symptoms of asthma and depression tend to overlap, specific symptoms of asthma may be linked to depression due to their effect on the individual's quality of life or due to asthmatic symptoms themselves.[9] Dyspnoea, waking at night with asthma and morning symptoms of asthma have a significant relation with depression.[9] Most of the patients have a positive Centre for Epidemiologic Studies Depression Scale (CESD-SF) screen, which is attributable mostly to a somatic sleep symptom that overlaps with asthma symptoms. The Geriatric Depression Scale (GDS) was more consistent with physician's reports of depressive disorders.[10] The association between asthma, depressive and anxiety symptoms may reflect effects of common factors rather than a direct causal link.

Depression can lead to a sense of hopelessness that erodes adherence and other health-promoting behaviour. Cognitive biases are evident in depression even after recovery from an acute episode, but are not found in neverdepressed patients with asthma. Depression has a high risk for poor adherence to asthma therapy after discharge.[7]

\section{Neurophysiological Aspects}

The relationship between depression and asthma has been explained using two hypotheses- the monoamine hypothesis and the cholinergic hypothesis. The monoamine hypothesis implicates deficiency of the neurotransmitters norepinephrine, serotonin and dopamine at important synaptic sites as responsible for depression. The cholinergic hypothesis states that the major pathophysiological mechanism in affective disorders is an imbalance between 
the adrenergic and cholinergic neurotransmitter systems; depression is associated with cholinergic dominance.[2] In this context it is pertinent to note that increased cholinergic activity and parasympathetic tone cause bronchoconstriction in the bronchial smooth muscles.[11]

Dysregulation of the hypothalamic-pituitary-adrenal axis (HPA axis) may predispose people to both major depressive disorders and asthma, and similar alterations in the immuneautonomic nervous and other key systems are apparent and may contribute to this increased risk of co-occurrence.[12] Hypersensitivity reactions may prime the HPA axis to respond aberrantly to stressors, resulting in physical and behavioural consequences.[13]

Emotional stress may exacerbate the physical symptoms of atopic disorders such as asthma. Some data suggest that psychological stress may shift the Th1/ Th2 cytokine balance towards type 2 and cause an immune dysregulation with more allergic or asthmatic reactions during periods of high stress. Psychological stress activates the HPA axis and sympathetic nervous system, leading to an increase in cortisol and catecholamine secretion. Cortisol and catecholamines can suppress Th1 cytokines such as IL-12 and IFN- $\gamma$ which may then shift the immune response toward a Th2 phenotype.[14] Increased levels of IL-4, IL-5 and IL-13 caused by alteration in immune response may further aggravate existing inflammation after an inhaled antigen exposure.[15]

\section{Aim of the Study}

The aim of this study is to study the prevalence of depressive disorders in asthmatic patients.

\section{Study Tools \\ Spirometric Criteria- Forced Expiratory Volume in One Minute (FEV1)}

It is the recommended method for measuring airway limitation and reversibility to establish diagnosis of asthma. This criterion is recommended by GINA 2008 (Global initiative for asthma) and is followed worldwide.

\section{Prime-MD Primary Health Questionnaire Scores}

The questionnaire was developed in 1994 by Spitzer et al. It is an efficient screening and evaluation tool for common mental disorders in the primary care setting. PRIME-MD is a 2 -stage system. The patient first completes a 26 -item selfadministered questionnaire.

The 2nd stage consists of a physician administered clinical evaluation guide, screening for 18 mental disorders.

\section{Patient Health Questionnaire (PHQ)}

A fully self-administered version of the PRIME-MD, developed in 1999 by Spitzer et al.

The 2 components of the original PRIME-MD were combined into a single, 3-page questionnaire that can be entirely self-administered by the patient (it can also be read to the patient, if necessary). It screens for 8 common mental disorders- Somatic syndrome, depressive disorder, panic syndrome, other anxiety disorders, alcohol abuse, bulimia nervosa and binge eating disorder.

\section{PHQ-9}

It consists of 9 questions used only to screen depression, derived from PHQ. It is patient's self-reporting questionnaire. This scale also helps to diagnose the severity if symptoms are based on the scoring. It is used widely to monitor the symptoms and response to treatment.

Semi-structured socio-demographic proforma prepared for the study consists of study parameters.

\section{Socio-Demographic Profile}

Age, gender, marital status, socio-economic status (Education, occupation, income), area of domicilerural/urban.

\section{Inclusion Criteria}

Patients aged 18 - 64 yrs., registering at the Department of Respiratory Medicine for the first time with a diagnosis of asthma subsequently confirmed through spirometry at the Department of Respiratory Medicine.

\section{Exclusion Criteria}

1. Patients with other co-morbid general medical conditions (hypertension, diabetes mellitus, etc.).

2. Patients who have received psychiatric treatment elsewhere and are on treatment currently.

3. Patients who cannot perform spirometry.

4. Presence of Chronic Obstructive Pulmonary Disease (COPD).

5. Smokers.

6. Severely ill patients unable to co-operate for psychiatric evaluation.

7. Patients who are not under steroids as the main form of treatment since steroids-induced depression will alter the results of the study.

\section{MATERIALS AND METHODS}

The Study Sample was of Convenience. It was a Descriptive Study-

All consecutive adult patients, aged 18 - 64 yrs., registering for the first time in the Department of Respiratory Medicine with respiratory symptoms suggestive of airway disease were assessed using spirometry. Cases that fulfilled standard spirometric criteria for the diagnosis of asthma entered step two of the case selection process. Patients with features of COPD and/ or history of smoking were excluded at this stage. All asthmatic patients selected through step one underwent comprehensive systemic examination and laboratory investigations (Haematology, Biochemistry) to exclude comorbid general medical conditions such as diabetes mellitus, hypertension, thyroid dysfunction, etc. All asthmatic patients without co-morbid general medical conditions were taken up for assessment of depression using PHQ-9, which is a screening tool for depression and later diagnosis of depression was confirmed using ICD-10 criteria. Statistic was only descriptive analysis. Ethical clearance was obtained from Ethical Committee of MGMCRI, Pondicherry.

\section{RESULTS}

\section{Age and Gender Distribution}

A total of 62 adult asthma patients participated in the study. Their median age was 33 years (range: 18 - 65). Of the participants, $39 \%$ were male and $61 \%$ were female with 
corresponding median (mean) ages of 30 (35.9) and 35 (37.3) years respectively (Figure 1). Both the median (95\% confidence intervals about median overlap for genders) and mean (Student's t-test for independent samples, $p=0.69$ ) ages do not differ significantly between genders. The study sample showed female preponderance and male-to-female ratio was 1: 1.5 .

\section{Marital Status}

Majority of patients in the sample were married.

\section{Socio-Economic Background}

The majority of the participants belonged to lower- and upper-lower income.

\section{Area of Domicile}

A large proportion of the study participants were from rural background.

\begin{tabular}{|c|c|c|}
\hline Variables & \multicolumn{2}{|c|}{$(\mathbf{n = 4 0 )}$} \\
\hline Age (year) & $40.4 \pm 13.7$ & \\
\hline Male & 25.5 & $(12)$ \\
\hline Female & 75.5 & $(28)$ \\
\hline Single & $12.6(8)$ & \\
\hline Married & 78.2 & $(28)$ \\
\hline Widowed & $9.45(4)$ & \\
\hline Upper & 3.1 & $(1)$ \\
\hline Upper Middle & 0.0 & $(0)$ \\
\hline Middle, Lower-Middle & 31.5 & $(12)$ \\
\hline Lower-, Upper-Lower & 50.3 & $(18)$ \\
\hline Lower & $15.7(9)$ & \\
\hline Rural & 56.5 & $(22)$ \\
\hline Urban & 43.8 & $(18)$ \\
\hline Table 1. Socio-Demographic Profile of the Asthmatic \\
Patients*
\end{tabular}

*Data are presented as mean \pm

Of the 70 asthmatic patients registered initially for the study, 40 had depressive disorders giving an overall prevalence of $57.1 \%$ with $15.7,24.3,14.3$ and $2.9 \%$ had mild, moderate, moderately severe and severe degree of depressions respectively (Figure 1).

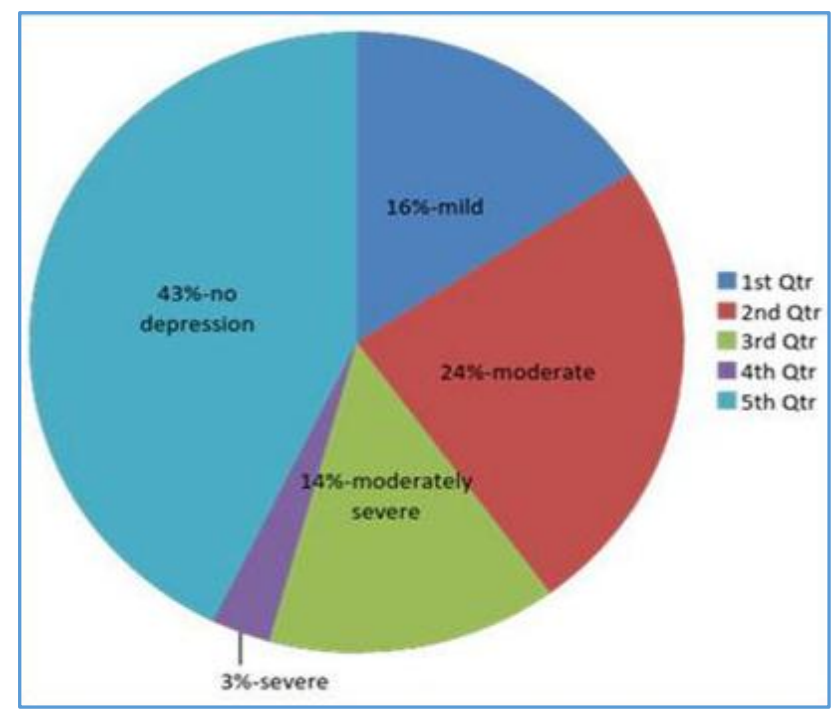

Figure 1. Prevalence of Depression

\section{DISCUSSION}

Socio-Demographic Factors- The study sample showed female preponderance and male-to-female ratio was $1: 1.5$. This is comparable to several other studies, where female asthmatic patients were more than males.[8] The majority of the participants belonged to lower- and upper-lower socioeconomic class followed by middle- and lower-middle socioeconomic class. This was similar to other study, which indicated that most of the study population belonging to lower income group.[16] A large proportion of the study participants were from rural area compared to those from urban area.

\section{Prevalence of Depression in Asthma Patients}

Majority $(n=40)$ of the asthmatic patients registered initially for the study had depressive disorders giving an overall prevalence of $57.1 \% ; 15.7 \%, 24.3 \%, 14.3 \%$ and $2.9 \%$ had mild, moderate, moderately severe and severe degree of depressions respectively. This can be compared to similar studies, which reported high prevalence of depression among asthmatics. A study by Yakar reported mild depression in $27 \%$ of asthmatics, moderate depression in $9 \%$ of asthmatics and severe depression in $7 \%$ of asthmatics.[16] The prevalence rate varied from $8 \%\left[{ }^{[8,17]}\right.$ to $55.01 \% .{ }^{[18]} \mathrm{A}$ multinational study by Adrian Loerbroks et al has found that the prevalence of depression in asthma patients to be on an average of $8.4 \%$ and Asia in specific is $7.1 \% .{ }^{[19]}$ Another study by Javier de Miguel Díez found 9\% prevalence of depression.[20] A study conducted in Egypt found prevalence of 13.3\%.[16] The prevalence in Indian studies ranged from $13.2 \%$ by Bharat Bhushan Sharma[21] to $65 \%$ by Misra et al.[22] Contradicting this, a review of literature done by Opolski reported mixed results as to whether persons with asthma are more likely to be depressed than those without asthma.

\section{CONCLUSION}

1. The study suggests that patients with asthma have high prevalence of depression.

2. The results indicate the need to screen all asthma patients for depression and other psychiatric comorbidities and treat them appropriately to improve their quality of life.[1,2]

\section{Limitations of the Study}

- One of the main limitations of this study was the relatively small size of the study sample.

- Issue of stigma with regard to mental illness seems to have adverse impact in the process of recruiting cases for the study.

\section{REFERENCES}

[1] Negi H, Sarkar M, Raval AD, et al. Presence of depression \& its risk factors in patients with chronic obstructive pulmonary disease. Indian J Med Res 2014;139(3):402-8.

[2] World Health Organisation. World Health Report 2001, Mental health: New understanding, New hope. Geneva (switzerland): World Health Organization; 2001.

[3] Hyman SE, Kandel E. Psychiatric disorders. In: Fauci AS. (eds). Harrison's principles of internal medicine. 17th edn. New York: McGraw-Hill Medical, 2008:270539. 
[4] Deshmukh VM, Toelle BG, Usherwood T, et al. The association of comorbid anxiety and depression with asthma-related quality of life and symptom perception in adults. Respirology 2008;13(5):695-702.

[5] Opolski M, Wilson I. Asthma and depression: a pragmatic review of the literature and recommendations for future research. Clin Pract Epidemiol Ment Health 2005;1:18.

[6] Zielinski TA, Brown ES, Nejtek VA, et al. Depression in asthma: prevalence and clinical implications. Prim Care Companion J Clin Psychiatry 2000;2(5):153-8.

[7] Smith A, Krishnan JA, Bilderback A, et al. Depressive symptoms and adherence to asthma therapy after hospital discharge. Chest 2006;130(4):1034-8.

[8] Goldney RD, Ruffin R, Fisher LJ, et al. Asthma symptoms associated with depression and lower quality of life: a population survey. Med J Aust 2003;178(9):437-41.

[9] Mancuso CA, Westermann $\mathrm{H}$, Choi TN, et al. Psychological and somatic symptoms in screening for depression in asthma patients. J Asthma 2008;45(3):221-5.

[10] Rubin NJ. Severe asthma and depression. Arch Fam Med 1993;2(4):433-40.

[11] Van Lieshout RJ, Bienenstock J, MacQueen GM. A review of candidate pathways underlying the association between asthma and major depressive disorder. Psychosom Med 2009;71(2):187-95.

[12] Hurwitz EL, Morgenstern H. Cross-sectional associations of asthma, hay fever, and other allergies with major depression and low-back pain among adults aged 20-39 years in the United States. Am J Epidemiol 1999;150(10):1107-16.

[13] Chrousos GP. Stress, chronic inflammation, and emotional and physical well-being: concurrent effects and chronic sequelae. J Allergy Clin Immunol 2000;106(5 Suppl):S275-91.
[14] Frieri M. Neuroimmunology and inflammation: implications for therapy of allergic and autoimmune diseases. Ann Allergy Asthma Immunol 2003;90(6 Suppl 3):34-40.

[15] Yakar T, Baran A, Gungor S, et al. The factors affecting beck depression scale in asthmatic patients. Tuberk Toraks 2007;55(1):11-7.

[16] Espinosa Leal FD, Parra RM, Mendez NH, et al. Anxiety and depression in asthmatic adults in comparison to healthy individuals. Rev Alerg Mex 2006;53(6):201-6.

[17] Goethe JW, Maljanian R, Wolf S, et al. The impact of depressive symptoms on the functional status of inner-city patients with asthma. Ann Allergy Asthma Immunol 2001;87(3):205-10.

[18] Loerbroks A, Herr RM, Subramanian S, et al. The association of asthma and wheezing with major depressive episodes: an analysis of 245727 women and men from 57 countries. Int J Epidemiol 2012;41(5):1436-44.

[19] de Miguel Díez J, Hernández Barrera V, Puente Maestu L, et al. Psychiatric comorbidity in asthma patients. Associated factors. J Asthma 2011;48(3):253-8.

[20] Farag TS, Hafez MR, Elshafie T, et al. Anxiety and depression among patients with Bronchial asthma, chronic obstructive pulmonary disease and diffuse parenchymatous lung diseases. The Egyptian Journal of Hospital Medicine 2012;49:718-31.

[21] Sharma BB, Singh S, Sharma VK, et al. Psychiatric morbidity in chronic respiratory disorders in an Indian service using GMHAT/PC. Gen Hosp Psychiatry 2013;35(1):39-44.

[22] Misra S, Kundu S, Majumder D, et al. A study of depression in adult patients with bronchial asthma presenting to a tertiary care hospital in eastern India. Indian J Chest Dis Allied Sci 2015;57(2):87-90. 